\title{
DEFECT LEVELS IN GALLIUM ARSENIDE AFTER IRRADIATION WITH LIGHT IONS
}

\author{
T. Schmidt, L. Palmetshofer
}

Abteilung Festkörperphysik, Johannes-Kepler-Universität Linz, 4045 Linz, Austria

AND K. LÜBKE

Institut für Mikroelektronik, Johannes-Kepler-Universität, 4045 Linz, Austria

Deep level centers in GaAs implanted with light ions $\left(\mathrm{H}^{+}, \mathrm{He}^{+}\right)$were studied by means of deep level transient spectroscopy, double correlation deep level transient spectroscopy and capacity voltage carrier profiling directly after the implantation process and after annealing at various temperatures. Five different electron traps with energy positions between $0.13-0.75 \mathrm{eV}$ are detected. From the evaluated defect production and carrier trapping yields and their annealing behavior we conclude that each of these traps efficiently contributes to the trapping of free carriers. The EL2 defect is created in too low concentrations in order to significantly account for the removal of free carriers.

PACS numbers: 68.55.Ln

The implantation of GaAs with light ions is a convenient technique used in GaAs device technology to insulate regions between neighboring devices due to the trapping of free electrons by the created defects. Subsequent annealing of the material at moderate temperatures $\left(250-600^{\circ} \mathrm{C}\right.$, depending on the implanted species) can further enhance the implant-induced resistivity of the bombarded area by almost one order of magnitude [1]. Although the implant-isolation technique has already been successfully used for years, still very little is known about the underlying compensation mechanisms and the defects leading to the capture of free carriers. In particular, the role played by the EL2 defect, which is known to be an efficient electron trap in GaAs, is still unclear. The aim of this paper was to investigate the influence of implantation and annealing parameters on the defect concentration and the overall carrier removal rate in order to gain a better understanding of the mechanisms responsible for optimum device isolation.

Silicon doped $n$-GaAs layers $\left(1 \times 10^{15}\right.$ to $\left.2 \times 10^{16} \mathrm{~cm}^{-3}\right)$ grown by metal organic chemical vapour deposition (MOCVD) on semi-insulating GaAs substrates were bombarded with $\mathrm{H}^{+}$and $\mathrm{He}^{+}$ions with energies between 200 and $300 \mathrm{keV}$ and doses ranging from $3 \times 10^{9}$ to $1 \times 10^{10} \mathrm{~cm}^{-2}$. The implantation energy was chosen such that the ion range and damage distribution were accessible to capacity volt- 


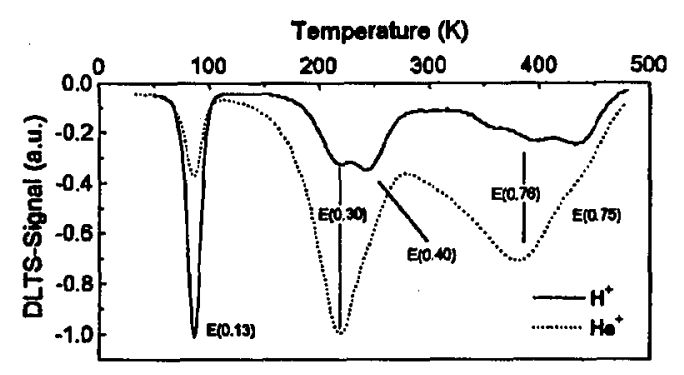

Fig. 1. DLTS spectra of a $\mathrm{H}^{+}$-irradiated GaAs sample $\left(200 \mathrm{keV}, 3 \times 10^{9} \mathrm{~cm}^{-2}\right.$, $n=1 \times 10^{15} \mathrm{~cm}^{-3}$ ) and a $\mathrm{He}^{+}$irradiated GaAs sample $\left(150 \mathrm{keV}, 3 \times 10^{9} \mathrm{~cm}^{-2}, n=\right.$ $1.1 \times 10^{16} \mathrm{~cm}^{-3}$ ). The signal intensities of both curves are normalized with respect to the strongest peak of each spectrum.

age (CV) analysis. The ion dose was kept low enough to avoid substantial carrier removal by deep levels. The measurements (CV profiling, deep level transient spectroscopy (DLTS), double correlation DLTS) were carried out on Schottky diodes. Two typical DLTS-spectra of a $\mathrm{H}^{+}$-irradiated sample $\left(200 \mathrm{keV}, 3 \times 10^{9} \mathrm{~cm}^{-2}\right)$ and a $\mathrm{He}^{+}$-irradiated sample $\left(150 \mathrm{keV}, 3 \times 10^{9} \mathrm{~cm}^{-2}\right)$, respectively, are shown in Fig. 1. The spectra give rise to the thermal emission from five different electron traps labeled $\mathrm{E}(0.13), \mathrm{E}(0.30), \mathrm{E}(0.40), \mathrm{E}(0.67)$ and $\mathrm{E}(0.75)$ with energy positions of $0.13,0.30,0.40,0.67$ and $0.75 \mathrm{eV}$ below the conduction band edge. All these levels occur both after $\mathrm{H}^{+}$and $\mathrm{He}^{+}$implantation, indicating that they are vacancy-correlated defects. However, they are created in remarkably different relative concentrations, reflecting different kinetic processes during the implantation with different ions. Besides the defect levels $\mathrm{E}(0.13)$, which have previously been assigned to the double negatively charged As vacancy [2] and the level $\mathrm{E}(0.75)$, which is the well-known EL2 defect, the physical nature of the other defects is still unclear. It has recently been speculated that these levels are due to primary defects in the As sublattice [2]. Figure 2a depicts depth profiles measured for the levels $\mathrm{E}(0.13), \mathrm{E}(0.40)$ and $\mathrm{E}(0.75)$ after $\mathrm{H}^{+}$bombardment $\left(200 \mathrm{keV}, 3 \times 10^{9} \mathrm{~cm}^{-2}\right)$. The corresponding computer simulation (TRIM, [3]) is shown in Fig. 2b. Both the shape and depth of the profiles for the defects $\mathrm{E}(0.13)$ and $\mathrm{E}(0.40)$ correlate well with the calculated vacancy distribution, supporting the assumption that these defects are purely vacancy-related. Similar distributions were obtained for the levels $\mathrm{E}(0.30)$ and $\mathrm{E}(0.67)$. The concentration offset of the level $\mathrm{E}(0.75)$ is due to a homogeneous background concentration of $1 \times 10^{13} \mathrm{~cm}^{-3}$, which was measured in our samples already prior to implantation.

CV carrier profiling shows a decrease in the electron concentration in the region of the defect distribution due to the capture of free carriers. By the subtraction of this concentration profile from the background doping level, a distribution is obtained reflecting the sum of all electrically active centers capturing free electrons.

The total number of defects observed related to the calculated number of vacancies produced (TRIM) is about 6.5 to $8 \%$ for $\mathrm{H}^{+}$implantation and $11 \%$ for 


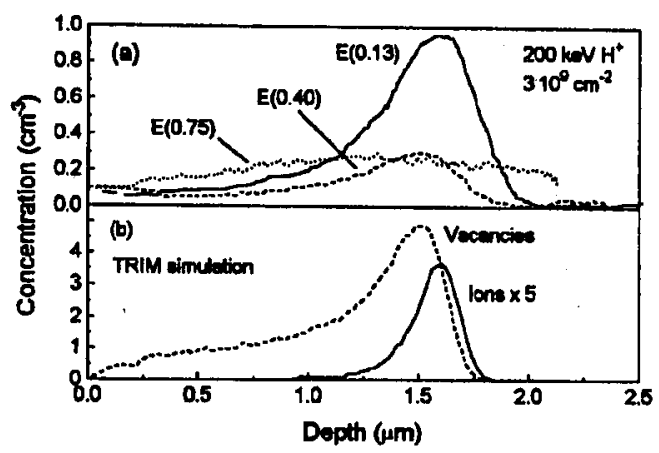

Fig. 2. (a) Depth profiles of the defects $E(0.13), E(0.40)$ and $E(0.75)$ recorded with the DDLTS technique after $\mathrm{H}^{+}$-irradiation of the sample $\left(200 \mathrm{keV}, 3 \times 10^{9} \mathrm{~cm}^{-2}\right)$. (b) Monte Carlo simulation (TRIM) of ion and vacancy distribution for $\mathrm{H}^{+}$-implantation in $\mathrm{GaAs}\left(200 \mathrm{keV}, 3 \times 10^{9} \mathrm{~cm}^{-2}\right)$.

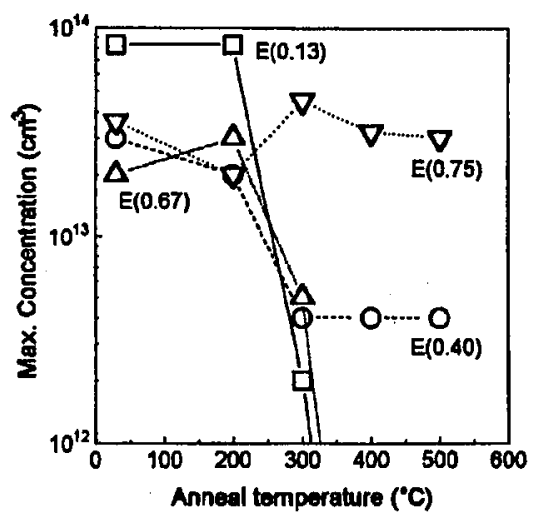

Fig. 3. Annealing behavior of the defects $\mathrm{E}(0.13), \mathrm{E}(0.40), \mathrm{E}(0.67)$ and $\mathrm{E}(0.75)$ for samples implanted with $200 \mathrm{keV} \mathrm{H} \mathrm{H}^{+}$at a dose of $3 \times 10^{9} \mathrm{~cm}^{-2}$. The indicated concentration refers to the concentration measured at the location of the profile maximum.

$\mathrm{He}^{+}$implantation, suggesting a very efficient recombination of interstitials and vacancies in the collision cascades. From the $\mathrm{CV}$ analysis we obtain a ratio of 3.6 removed carriers per implanted ion for $\mathrm{H}^{+}$bombardment and 21 for $\mathrm{He}^{+}$ bombardment. DLTS measurements give similar figures for the total number of defects created per incident ion. This result suggests that all electrically active traps are actually observed and each of them is actively involved in the carrier removal process.

The annealing behavior of the defects is depicted in Fig. 3. Between $200^{\circ} \mathrm{C}$ and $300^{\circ} \mathrm{C}$ all defects apart from the EL2, which is known to remain unaffected up to $\mathrm{T} \cong 1050^{\circ} \mathrm{C}$ [4], anneal almost completely. For the concentration of trapped carriers, a consistent evolution with the annealing temperature is observed. The free carrier concentration $n$ increases with thermal treatment and approaches 
the pre-implantation background doping level for annealing temperatures above $300^{\circ} \mathrm{C}$.

Neither the observed annealing behavior of the created defects nor the steady recovery of $n$ towards its original value features the typical evolution of the resistivity with the annealing temperature reported in literature $[1,5-7]$. For $\mathrm{H}^{+}$ implanted $\mathrm{GaAs}$ a maximum of the sheet resistivity at about $250^{\circ} \mathrm{C}$ is observed, followed by a decrease towards its original pre-implantation value for higher annealing temperatures [1]. All these investigations have been carried out after bombardment with high ion doses, and it has already been suggested [1] that because of hopping conductivity effects, the as-implanted value of resistivity is not the maximum achievable. This model is consistent with our results showing that no maximum of the resistivity occurs for low implantation doses. The annealing behavior measured for the defect levels $\mathrm{E}(0.13), \mathrm{E}(0.67)$ and $\mathrm{E}(0.40)$ coincides well with the reported steep decrease in resistivity above $250^{\circ} \mathrm{C}$. The $\mathrm{E}(0.75)$ level (EL2), which is known as an efficient electron trap, plays a minor role in device isolation. Its concentration remains unaffected in the investigated temperature range, but the defect is created in far too low concentration in order to significantly contribute to the removal of free carriers. This conclusion holds also for bombardment with heavier ions, e.g. Si [8].

\section{References}

[1] S.J Pearton, Mater. Sci. Rep. 4, 313 (1990).

[2] D. Pons, J.C. Bourgoin, J. Phys. C, Solid State Phys. 18, 3839 (1985).

[3] J.F. Ziegler, J.P. Biersack, U. Littmark, The Stopping and Range of Ions in Solids, Vol. 1, Pergamon, New York 1985.

[4] J. Lagowski, H.C. Gatos, C.H. Kang, M. Skowronski, K.Y. Ko, D.G. Liu, Appl. Phys. Lett. 49, 892 (1986).

[5] Y. Yuba, K. Gamo, K. Murakami, S. Naraba, Inst. Phys. Conf. Ser. 59, 329 (1981).

[6] I.J. Saunders, K. Steeples, in: Semi-Insulating III-V Materials, Ed. G.J. Rees, Shiva, Cheshire (UK) 1980, pp. 122-129.

[7] A.E. von Neida, S.J. Pearton, W.S. Hobson, C.R. Abernathy, Appl. Phys. Lett. 54, 1540 (1989).

[8] L. Palmetshofer, J. Kastner, K. Lübke, Nucl. Instrum. Methods Phys. Res. B 59/60, 1081 (1991). 